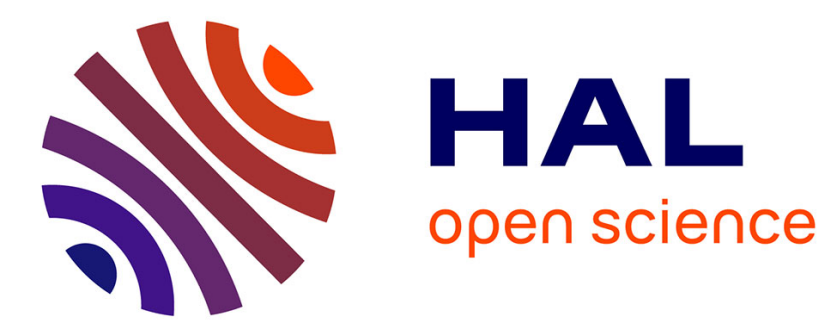

\title{
Numerical investigations on hydrogen-enhanced combustion in ultra-lean gasoline spark-ignition engines
}

Nicolas Iafrate, Mickaël Matrat, Jean-Marc Zaccardi

\section{To cite this version:}

Nicolas Iafrate, Mickaël Matrat, Jean-Marc Zaccardi. Numerical investigations on hydrogen-enhanced combustion in ultra-lean gasoline spark-ignition engines. International Journal of Engine Research, 2021, 22 (2), pp.375-389. 10.1177/1468087419870688 . hal-02294152

\section{HAL Id: hal-02294152 \\ https://hal-ifp.archives-ouvertes.fr/hal-02294152}

Submitted on 23 Sep 2019

HAL is a multi-disciplinary open access archive for the deposit and dissemination of scientific research documents, whether they are published or not. The documents may come from teaching and research institutions in France or abroad, or from public or private research centers.
L'archive ouverte pluridisciplinaire HAL, est destinée au dépôt et à la diffusion de documents scientifiques de niveau recherche, publiés ou non, émanant des établissements d'enseignement et de recherche français ou étrangers, des laboratoires publics ou privés. 
Numerical investigations on hydrogen-enhanced combustion in
ultra-lean gasoline spark-ignition
engines

\author{
Nicolas lafrate, Mickael Matrat, Jean-Marc Zaccardi
}

\begin{abstract}
Performance of lean burn gasoline spark-ignition engines can be enhanced through hydrogen supplementation. Thanks to its physicochemical properties, hydrogen supports the flame propagation and extends the dilution limits with improved combustion stability. These interesting features usually result in decreased emissions and improved efficiencies. This article aims at demonstrating how hydrogen can support the combustion process with a modern combustion system optimized for high dilution resistance and efficiency. To achieve this, chemical kinetics calculations are first performed in order to quantify the impacts of hydrogen addition on the laminar flame speed and on the auto-ignition delay times of air/gasoline mixtures. These data are then implemented in the ECFM and TKI combustion models in a specifically updated version of the CONVERGE code. 3D CFD engine calculations are performed at $\lambda=2$ with $3 \mathrm{v} / \mathrm{v} . \%$ of hydrogen for two operating points. At low load, numerical investigations show that hydrogen enhances the maximal combustion speed and the flame growth just after the spark which is a critical aspect of combustion with diluted mixtures. The flame front propagation is also more isotropic when supported with hydrogen. At mid load, hydrogen improves the combustion speed but also extends the auto-ignition delay times resulting in a better knocking resistance. A maximal indicated efficiency of $48.5 \%$ can thus be reached at $\lambda=2$ thanks to an optimal combustion timing.
\end{abstract}

\title{
Keywords
}

Lean combustion, RANS simulation, hydrogen, combustion enhancer, spark engine combustion

\section{Introduction}

To reduce fuel consumption and pollutant emissions of Spark-Ignition (SI) engines, car manufacturers have increasingly focused on alternative fuels and lean burn combustion. Enhanced aerodynamic and ignition characteristics are two key parameters that impact the lean combustion stability (1). Besides these technical aspects, fuel formulation can also contribute to perform stable lean combustion. Hydrogen has proved to be a good alternative fuel for vehicles when used as the single source of chemical energy or as a supplemental combustion enhancer for Diesel or SI engines $(2 ; 3)$. The unique combustion properties of hydrogen can lead to significant benefits in terms of engine efficiency and emissions performance. For example the adiabatic flame speed is five times larger for hydrogen $(237 \mathrm{~cm} / \mathrm{s})$ than for gasoline (42 $\mathrm{cm} / \mathrm{s}$ ) which contributes to extend the engine operating range with an acceptable combustion stability. Furthermore, the diffusion coefficient of hydrogen is around four times as large as that of gasoline ( 0.61 and $0.16 \mathrm{~cm}^{2} / \mathrm{s}$ respectively), which improves the hydrogen-air mixing process. Despite all these advantages, the pure hydrogen-fueled engine could not be widely commercialized because of several reasons and notably because of its poor NOx emissions performance (4) related to its high adiabatic flame temperature. Moreover, the energy density of hydrogen is much lower than that of gasoline, leading to a weak torque output (5). However, using a small amount of hydrogen as an additive to hydrocarbonfueled engines is a good compromise to take advantage of the good properties of both fuels. Such a strategy is already well known in the literature and several good results have already been reported $(6 ; 7 ; 8 ; 9)$. It is particularly the case for lean burn SI engines for which hydrogen supplementation was considered since the 1970s (10) in order to improve the dilution resistance, to improve engine thermal efficiency and to reduce pollutant emissions $(11 ; 12)$. Ji el al. $(13 ; 14 ; 15)$ conducted a series of experimental investigations on the hybrid hydrogen-gasoline engine. The results showed that hydrogen blending availed heightening the engine thermal efficiency, reducing pollutants and reducing the cycle to cycle variation. Several experimental studies have been performed to better understand the performance of hydrogenenriched or hydrogen-supplemented engines. For example, Varde et al. (16) have investigated the effect of hydrogen addition on the engine lean operating stability with a singlecylinder carburetor engine. They conclude that hydrogen addition lead to an increase of the flame development and propagation. The hydrogen addition under lean and diluted conditions was investigated by Tahtouh et al. on a single cylinder engine (17). They demonstrated that hydrogen addition combined with lean and diluted operation can impact

IFP Energies nouvelles, Institut Carnot IFPEN TE., France

Corresponding author:

Mickael Matrat, IFPEN, 1-4 Avenue du Bois Préau, 92852 RueilMalmaison, France.

Email: mickael.matrat@ifpen.fr 
positively $\mathrm{HC}, \mathrm{CO}$ and nitrogen oxides emissions. The effect of various equivalence ratios and speeds on combustion of a gasoline engine with hydrogen addition was also studied by D'Andrea et al. (18), on a modified carburetor engine with a premixed air/hydrogen mixture at the intake, which highlight that the hydrogen increase the combustion speed.

In the future, ultra-lean mixtures in spark-ignition engines will be required to achieve very high efficiency and hydrogen supplementation is a potential solution to support the combustion process in those ultra-lean conditions targeting $\lambda \geq 2$, and maximal brake thermal efficiencies higher than $50 \%$. Other combustion systems relying on pure hydrogen combustion could also be considered as suggested by Gerke et al. (19) who focus on key parameters such as the flame speed to model this system.

The aim of this study is to compare the results of some experimental investigations with 3D CFD calculations in order to highlight the effect of hydrogen on the combustion process for different operating points. A threesteps methodology has been defined for this work. In the first step, chemical kinetics calculations were performed in homogeneous reactors to determine the impact of hydrogen on the laminar flame velocity and on the auto-ignition delay times of air/gasoline mixtures. In a second step, the combustion models and the CONVERGE calculation code were updated to incorporate the information provided by detailed chemical kinetics calculations. Validation calculations were then performed with CONVERGE on simple reference cases. Finally, 3D engine calculations were carried out for two operating points in order to highlight the positive effects of hydrogen on combustion in SI engines. The following sections detail first the chemical kinetics calculations and the engine characteristics. Then, the numerical setup for engine calculations is detailed as well as the numerical results obtained for two operating points.

\section{Kinetic modeling of the $H_{2}$ boosted combustion}

Chemical kinetic models enable to explore the detailed reactivity of selected compounds within certain ranges of thermodynamic conditions or mixtures compositions. Estimation of global combustion properties such as autoignition delays or laminar flame speeds is possible but the model ability to extrapolate these parameters outside of their validation ranges can be uncertain and mostly depends on the way they were established. In order to develop the inputs required for the 3D calculations performed in the frame of this study with hydrogen, two distincts mechanisms were used based on their ability to perform well for the existing experimental data regarding auto-ignition delays or laminar flame speeds. Due to limited data for the developed surrogate fuel in combination with hydrogen, it must be emphasized that the chemical inputs developed here mainly aim to capture the qualitative trends when an extrapolation is required. Various tests were performed and presented here to ensure the representativity of the chemical inputs provided to the CONVERGE simulations.

\section{Surrogate fuel establishment}

Each mechanism selected to simulate the auto-ignition delays or the laminar flame speeds requires a satisfactory estimation of the gasoline surrogate compounds and hydrogen properties. Common compounds used to model gasoline combustion comprise mainly a mix of three species namely n-heptane, iso-octane and toluene with the addition of ethanol to account for the use of oxygenated fuels as blending components (20). In order to propose a surrogate composition that is representative of the gasoline fuel simulated, the reaction workbench from CHEMKIN Pro was used (21). It includes a fuel surrogate formulation that enables to match both the physical and chemical properties of the real fuel. The four compounds cited above were used and key properties including the lower heating value, octane numbers, ratios of each chemical family (e.g. alkane, aromatic, alcohol) as well as the elemental composition were targetted. The surrogate defined, here named TRFE for Toluene Reference Fuel containing Ethanol, includes 30.8 $\%$ of toluene, $42.4 \%$ of iso-octane, $17.6 \%$ of n-heptane and $9.2 \%$ of ethanol in liquid volume. This matches within $3 \mathrm{v} / \mathrm{v} . \%$ (liquid volume) the E10 gasoline fuel composition for each chemical family. In addition, the octane numbers estimated based on individual components were 94.7 and 87.8 for the research octane number and the motor octane number respectively. This gasoline fuel surrogate was used in combination of two kinetic mechanisms chosen for autoignition and laminar flame speed modeling.

\section{Laminar flame speed modeling}

The first mechanism dedicated to laminar flame speeds calculations is based on the reduced kinetic model developed for gasoline surrogate as well as natural gas by Bounaceur et al. (22) to which a skeletal sub-mechanism for toluene oxidation has been implemented. The mechanism used includes 2118 reactions and 276 species. Its validation is established within common pressure, temperature and equivalence ratios ranges considering the current thermodynamic experimental limitations of dedicated apparatus. Indeed, the temperature range considered is usually $298 \mathrm{~K}-500 \mathrm{~K}$ for heavier hydrocarbons than $C_{3}$ and a maximum pressure lower than 25 atm (23; 20). These conditions are consequently at the edge of the targetted cases in this work. Qualitative trends are thus the objective for each parameter variation considered. Here the laminar flame speed is numerically simulated using the PREMIX and AURORA libraries of CHEMKIN-PRO package version 15131 (21). For all calculations results presented here and used for the flame speed correlation development, simulations converged for gradient and curvature criteria equal to 0.5 . Mixture-averaged transport was used in order to screen a larger set of thermodynamic and mixtures conditions for the flame speed correlation establishment. It was found that this methodology provides satisfactory estimations of the flame speeds trends versus the several parameters considered.

As presented previously (22), the mechanism proposed enables to simulate with a good agreement flame speeds of single hydrocarbons and mixtures thereof up to $C_{7}$ and $C_{8}$. In addition, its ability to model pure hydrogen combustion is illustrated Figures 1a, 1b and 2. The order of magnitude 
and the trends are well simulated for the pressure and $\lambda$ variations.

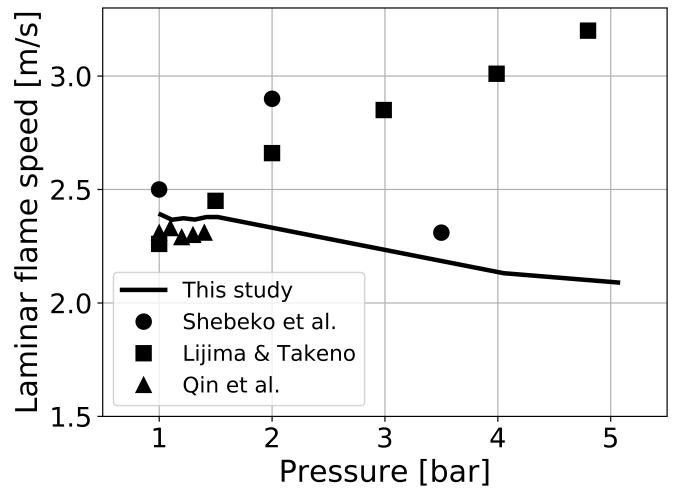

(a) $\lambda=1$

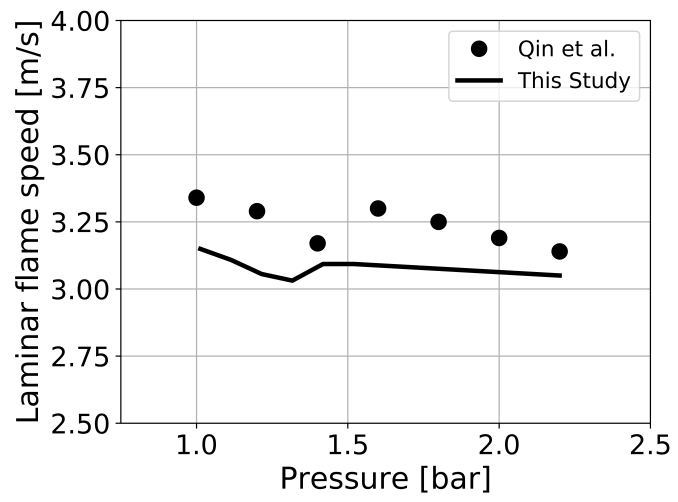

(b) $\lambda=0.5$

Figure 1. Modeling of the laminar flame speed of pure $\mathrm{H}_{2}$ in air versus pressure and for two equivalence ratios. Experimental data were collected from Shebeko et al. (24), lijima and Takeno (25) and Qin et al. (26).

The pressure effect illustrated Figure 1 is correctly captured by the model. Indeed, the data set from Iijima et al. (25) overestimates the laminar flame speed at high pressure as the flame stretch is not considered in their study. This finding has been confirmed by Aung et al. (27) who measured a laminar flame speed close to $2 \mathrm{~m} / \mathrm{s}$ at 4 bar. The temperature effect illustrated in Figure 2 is correctly captured for lean mixtures while a consistent deviation is observed as the temperature increases or $\lambda$ decreases. The simulations refinement used is identical to the parameters selected for the flame speed database establishement. This clearly affects the results and can be the reason for this discrepancy as a higher refinement (i.e. gradient and curvature down to 0.05) modifies the laminar flame speeds values up to $15 \%$ for a large set of tested cases.

Considering the hydrogen effect on fuel surrogate flame speed, the doping level considered here does not exceed $6 \mathrm{v} / \mathrm{v} . \%$ of the intake air flow rate. A volumetric value of hydrogen within the fuel composition higher than $70 \%$ can then be reached in this study. A few studies highlight an increase of the laminar flame speed for iso-octane when hydrogen is added independantly of the equivalence ratio $(29 ; 30 ; 31)$. As an example, the laminar flame speed increase at $423 \mathrm{~K}$ and $\lambda=1.25$ is close to $10 \%$ and $20 \%$ for a volumetric hydrogen addition to iso-octane of $50 \%$ and $70 \%$

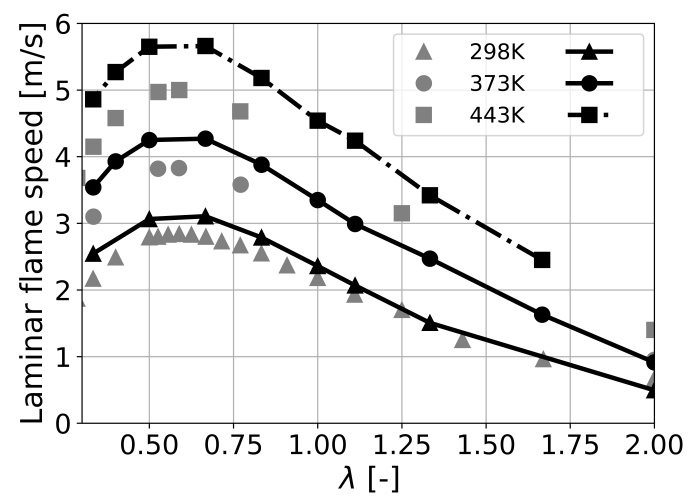

Figure 2. Modeling of the laminar flame speed of pure $\mathrm{H}_{2}$ in air versus $\lambda$ for three temperatures: $298 \mathrm{~K}, 373 \mathrm{~K}$ and $443 \mathrm{~K}$. The experimental data, extracted from Krejci et al. (28), are represented in symbols and the new correlation in lines.

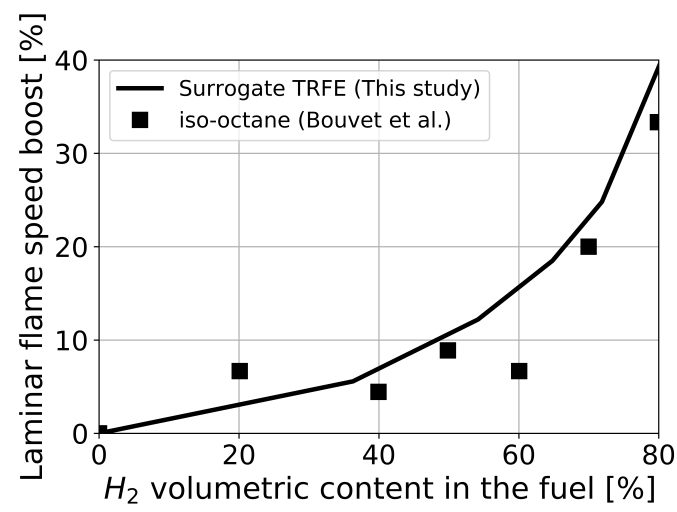

Figure 3. Modeling of the laminar flame speed boost for the fuel surrogate used in this study compared to the measured boost effect on iso-octane at $443 \mathrm{~K}$ and $\lambda=1.25$ (29).

respectively (29). Figure 3 compares the laminar flame speed boost effect of hydrogen for the fuel surrogate considered here for similar thermodynamic conditions than the later study with iso-octane.

While the fuels are different, the predicted boost is similar. The result suggests that hydrogen addition to hydrocarbons leads to a similar effect. This statement is supported by Bouvet et al. (29) for smaller hydrocarbons such as propane or methane even if the later displays a higher boost relative to pure methane flame speed for lower amounts of hydrogen added.

In order to evaluate and store the hydrogen boost on a large set of parameters for the 3D calculations, the kinetic mechanism was then used to develop a flame speed correlation. A matlab algorithm including a nonlinear optimization function was used to obtain the equation coefficients. The mathematical equation form as well as the coefficients are provided in Table 1.

$$
\begin{aligned}
S_{L}= & S_{L 0}\left(\frac{T}{T_{0}}\right)^{h}\left(\frac{P}{P_{0}}\right)^{i}\left(1+j X H_{2}(\Phi-1)\right) \\
& \left(1+k \cdot E G R^{2}+\text { l.EGR }\right)\left(1-m . E G R . X H_{2}\right)
\end{aligned}
$$


Where

$$
S_{L 0}=\left(1+a\left(X H_{2}\right)^{b}\right) c \Phi^{d} \exp \left(e(|\Phi+f|)^{2}\right)
$$

Constants are reported in Table 1. The flame speed is reported in $\mathrm{cm} / \mathrm{s}$ and $S_{L 0}$ corresponds to the laminar flame speed in the reference conditions used here which are $500 \mathrm{~K}$ and $10 \mathrm{~atm}$. The units are : Temperature in Kelvin, Pressure in atmosphere, $\mathrm{H}_{2}$ ratio in mol\% of air and the Exhaust Gas Recirculation (EGR) in mol\%.

\begin{tabular}{cc}
\hline \hline Symbol & Constant \\
$\mathrm{a}$ & 0.04703 \\
$\mathrm{~b}$ & 1.0653 \\
$\mathrm{c}$ & 36476.8183 \\
$\mathrm{~d}$ & 5.7836 \\
$\mathrm{e}$ & -1.2436 \\
$\mathrm{f}$ & 1.2857 \\
$\mathrm{~h}$ & $2.3139+2.7353\left((\Phi-1)^{2}\right)-0.58956(\Phi-1)$ \\
$\mathrm{i}$ & $-0.33945-0.021676\left((\Phi-1)^{2}\right)+0.13269(\Phi-1)$ \\
$\mathrm{j}$ & -0.03584 \\
$\mathrm{k}$ & 0.00016 \\
$\mathrm{l}$ & -0.032399 \\
$\mathrm{~m}$ & -0.00058 \\
\hline \hline
\end{tabular}

Table 1. Constants for the laminar flame speed correlation.

This equation combines previously established mathematical functions to model the laminar flame speed trends for hydrocarbons versus temperature, pressure, $\lambda$ or EGR $(32 ; 33 ; 34)$. The combined modeling of hydrogen boost and EGR required an additional term being a function of both parameters. The hydrogen effect of the fuel laminar flame speed in a diluted environment is indeed affected by the diluent composition but no data exists for this very specific case combining detailed EGR composition (i.e. $\mathrm{N}_{2}, \mathrm{H}_{2} \mathrm{O}$ and $\mathrm{CO}_{2}$ ) and a TRFE. Hydrogen addition certainly increases the flame speed as it is shown in the litterature for different fuels and diluents such as iso-octane- $\mathrm{H}_{2} / \mathrm{N}_{2}$ (35) or $\mathrm{H}_{2} / \mathrm{N}_{2}$ $\mathrm{H}_{2} \mathrm{O}$ (36). However the quantitative effect predicted by the chemical mechanism and thus the correlation is uncertain and requires further work which is beyond the scope of this study. Consequently, care must be taken when considering this combined parameter variation as the quantitative effect is not validated. More than one thousand single calculations were performed and used to establish the correlation. The several parameters ranges considered are listed in Table 2. It should be emphasized that while this study aims to simulate a lean combustion, the correlation must provide reasonable values for rich mixtures as heterogeneities are present in $3 \mathrm{D}$ calculations.

\begin{tabular}{ccc}
\hline \hline Parameters & Min. & Max. \\
$H_{2}$ in air intake (v/v.\%) & 0 & 6 \\
Temperature (K) & 500 & 850 \\
Pressure (bar) & 10 & 120 \\
$\lambda(-)$ & 0.58 & 2 \\
EGR $(\mathrm{mol} / \mathrm{mol} \%)$ & 0 & 10 \\
\hline \hline
\end{tabular}

Table 2. $\overline{\overline{\text { Parameters ranges considered for the developed }}}$ laminar flame speed correlation.

The absoluste flame speed deviation for the entire data is illustrated in Figure 4.

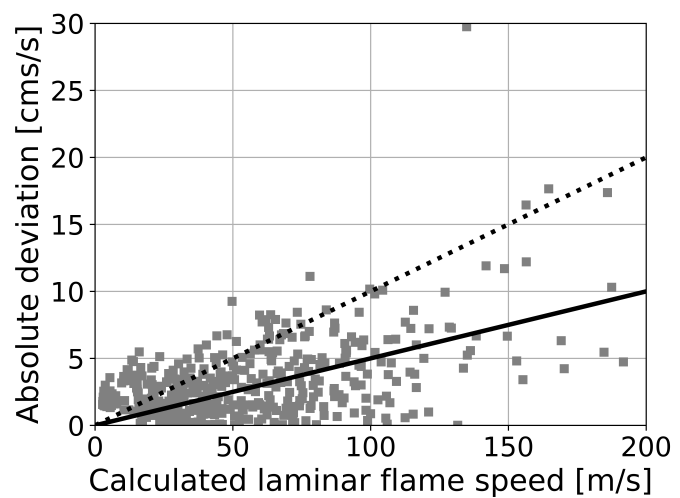

Figure 4. Absolute deviation obtained for the entire dataset used to establish the laminar flame speed correlation. The solid and dashed black lines represent respectively the deviation of $5 \%$ and $10 \%$.

It displays a deviation lower than $6.7 \mathrm{~cm} / \mathrm{s}$ for flame speeds below $25 \mathrm{~cm} / \mathrm{s}$. For higher flame speeds, this highest deviation is $23 \%$ which is a data point on the edge of the considered parameters ranges. Consequently, the correlation provides a satisfactory agreement with the simulation results. Figure 5 illustrates the results obtained for the parameters tested and emphasizes the hydrogen effect simulated in the reference case studied here which is $\lambda=2$.

\section{Auto-ignition modeling}

The Tabulated Kinetics of Ignition (TKI) model $(37 ; 38)$, accounts for auto-ignition in the frame of this study. It relies on tabulated auto-ignition parameters deduced from detailed chemistry calculations. In particular, the reaction rate due to auto-ignition is deduced from linear interpolation in a lookup table for local conditions of mean pressure, fresh gases temperature, fuel/air equivalence ratio, EGR volume fraction and auto-ignition progress variable. In order to capture the expected behaviors of a complexe gasoline fuel over a large set of thermodynamic conditions, a detailed kinetic mechanism validated for a gasoline surrogate fuel and for engine relevant conditions was used. The mechanism was developed by the Lawrence Livermore National Laboratory (LLNL) (39) and simulates the autoignition delay of the selected species in this study. It includes about 6000 reactions and 1550 species. The hydrogen effect on the ignition delay for this mechanism has been discussed by Jain et al. (40). The later observed that the ignition delay increases compared to pure iso-octane below $1100 \mathrm{~K}$. This auto-ignition delay increase is explained by an additionnal reaction pathway when hydrogen is added. The later reacts with $\mathrm{OH}$ radicals to produce water and this step slows the ignition process. Indeed, the hydrogen addition displays a large effect on the auto-ignition delay as demonstrated experimentally by An et al. (41). Rapid compression machine experiments from $735 \mathrm{~K}$ to $847 \mathrm{~K}$ indicate that both iso-octane and n-heptane auto-ignition delays were increased with hydrogen addition. These results highlight that the hydrogen boost depends both on $\lambda$ and the fuel. This justifies the need for a dedicated kinetic model in order to account for these parameters. To illustrate the 


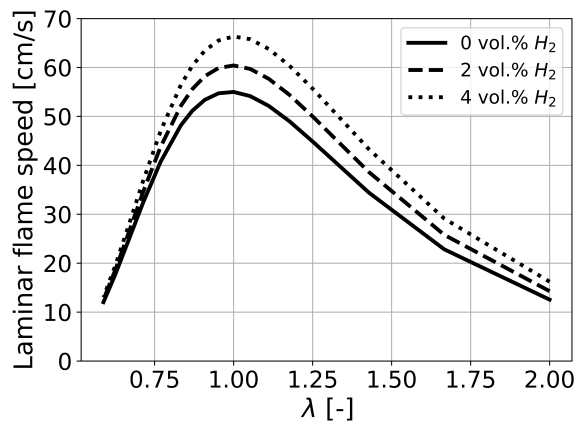

(a) $\lambda$ effect $(P=10$ atm, $\mathrm{T}=500 \mathrm{~K}$, no dilution)

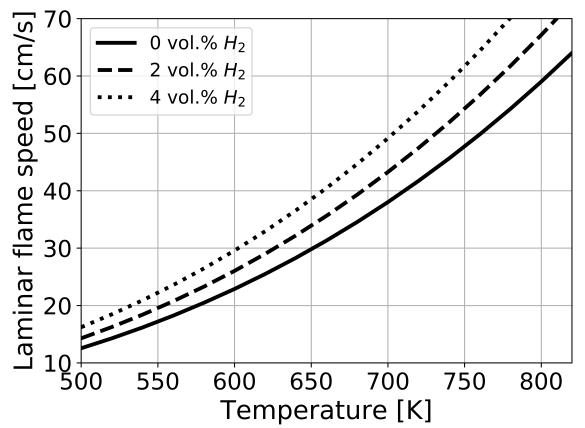

(b) Temperature effect ( $\lambda=2, \mathrm{P}=10$ atm, no dilution)

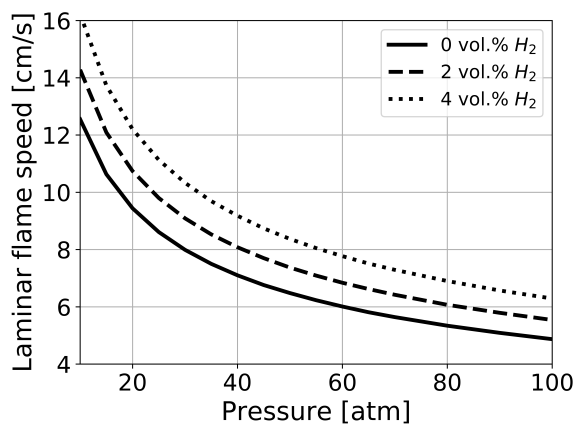

(c) Pressure effect ( $\lambda=2, T=500 \mathrm{~K}$, no dilution)

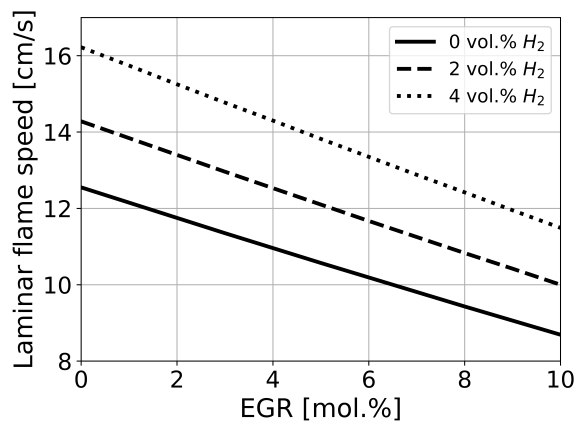

(d) Dilution effect $(\lambda=2, P=10 \mathrm{~atm}, \mathrm{~T}=500 \mathrm{~K})$

Figure 5. Illustrations of the laminar flame speed correlation results for parameters variations including $\lambda$, temperature, pressure and dilution.

hydrogen effect with the TRFE, Figure 6 displays the autoignition delays for two $\lambda$ values and three hydrogen levels considered in this study.

The increasing auto-ignition delay at lower temperature is indeed observed. In addition, a temperature limit at which hydrogen addition starts to display the opposite effect is

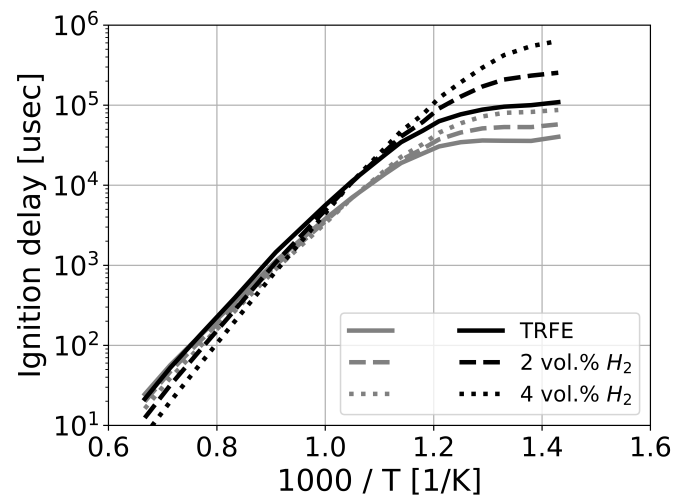

Figure 6. Ignition delay modeling in a closed batch reactor under constant volume, 10 bar and no dilution for $\lambda=1$ (grey) and 2 (black) and three hydrogen levels : 0 (fuel surrogate), 2 and $4 \mathrm{v} / \mathrm{v} . \%$. The hydrogen level is expressed in volumetric percents of air.

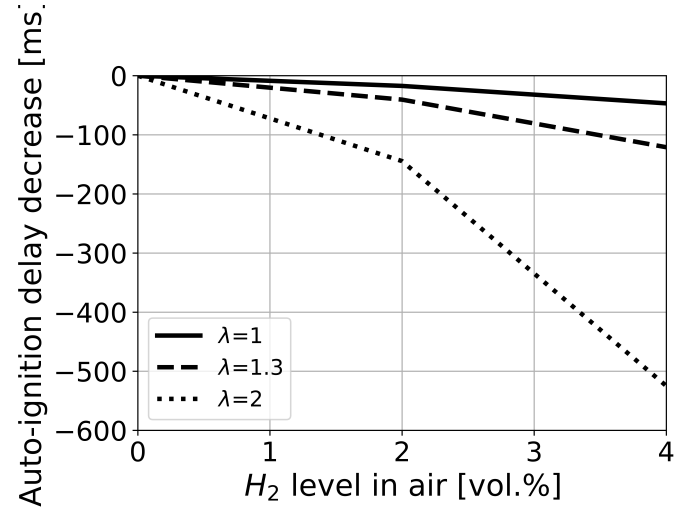

Figure 7. Ignition delay decrease up to $4 \mathrm{v} / \mathrm{v} . \%$ of hydrogen added to air at $700 \mathrm{~K}, 10$ bar and no dilution for three $\lambda: 1,1.3$ and 2 .

also confirmed based on the simulation performed by Jain et al. (40). The ignition delay decrease is related to two key reaction pathways at high temperature : $\mathrm{O}_{2}+\mathrm{H}=\mathrm{OH}+\mathrm{O}$ and $\mathrm{H}_{2} \mathrm{O}_{2}+\mathrm{M}=\mathrm{OH}+\mathrm{OH}+\mathrm{M}$. This negative effect of hydrogen should not have any impact on auto-ignition in lean SI engines since the fresh gases temperature should remain below $1000 \mathrm{~K}$ even when considering high compression ratios. To evaluate the boost effect on the ignition delay at a rather low temperature and for several equivalence ratios, a focus is made in Figure 7 at $700 \mathrm{~K}$ and $10 \mathrm{bar}$.

As $\lambda$ increases, the ignition is further delayed for the same hydrogen level. This effect could be beneficial regarding knock as leaner mixture would contribute to limit the autoignition occurence in the engine. It is suggested that this would even be intensified for higher hydrogen levels.

The TKI-Table development was performed with an inhouse code named CLOE based on the Senkin solver from CHEMKIN II. More than 300,000 zero dimensionnal calculations were performed and their results stored to capture the progress variable that is related to the ignition delay. The parameters ranges considered are listed in Table 3. Those are different than the ones presented for laminar flame speed calculations as the ignition time evaluation implies 
to consider the system history for which large parameters variations are encountered.

\begin{tabular}{ccc}
\hline \hline Parameters & Min. & Max. \\
$H_{2}$ in air intake (v/v.\%) & 0 & 6 \\
Temperature (K) & 500 & 1500 \\
Pressure (bar) & 1 & 120 \\
$\lambda(-)$ & 0.3 & 3.3 \\
EGR (mol/mol\%) & 0 & 10 \\
\hline \hline
\end{tabular}

Table 3. $\overline{\overline{\text { Parameters ranges considered for the developed }}}$ auto-ignition table.

\section{Engine overview and operating conditions}

The engine used for both experimental and numerical investigations is characterized by a high stroke-to-bore ratio of 1.24 , a high compression ratio of $14: 1$ and a high tumble motion of 2.4 combined with an Early Inlet Valve Closing (EIVC) timing strategy (see Table 4). This modern combustion system is fully representative of the most efficient serial production engines to date and has been thoroughly optimized for a high dilution resistance and high efficiency.

\begin{tabular}{ccc}
\hline \hline Cylinder Displacement & {$\left[\mathrm{cm}^{3}\right]$} & 410.9 \\
Valves & {$[-]$} & 4 \\
Stroke & {$[\mathrm{mm}]$} & 93.0 \\
Bore & {$[\mathrm{mm}]$} & 75.0 \\
Compression ratio & {$[-]$} & $14: 1$ \\
Tumble level & {$[-]$} & 2.4 \\
Intake valve lift & {$[\mathrm{CAD}]$} & 140 \\
EVC/IVO @ 1 mm lift & {$[\mathrm{CAD}$ aTDC] } & $-10 / 10$ \\
Injection & {$[-]$} & Central direct \\
\hline \hline
\end{tabular}

Table 4. Engine characteristics.

Ignition is triggered with a classical spark-plug and a conventional ignition energy. However, it will be shown below that ignition can be performed efficiently under high pressure conditions and for ultra-lean mixtures thanks to hydrogen supplementation.

Impacts of $H_{2}$ on the combustion process have been both experimentally and numerically assessed for two operating points, summarized in Table 5.

\begin{tabular}{ccccc}
\hline \hline Speed & IMEP & $\lambda$ & ST & SOI \\
{$[\mathrm{rpm}]$} & {$[\mathrm{bar}]$} & {$[-]$} & {$[$ CAD bTDC] } & [CAD bTDC] \\
2000 & 4 & 2 & 27.5 & 290 \\
3000 & 13 & 2 & 21.5 & 290 \\
\hline \hline
\end{tabular}

Table 5. Investigated operating points.

During the experimental testing phase, the dilution rate by air $\lambda$ was varied for each of these operating points in order to quantify the impacts of hydrogen on the combustion stability limits with diluted mixtures (the maximal air dilution rate being reached when the coefficient of variation of IMEP exceeds $3 \%$ ) and the minimal amounts of hydrogen required to reach $\lambda=2$. Then, for the calculation phase, different topics were investigated depending on the load:
- At low load (2000 rpm - 4 bar IMEP at $\lambda=2$ ): the main objective was to highlight the positive impacts of $\mathrm{H}_{2}$ on combustion speed with an optimal combustion timing. For this operating point, two calculations have been performed, with $3 \mathrm{v} / \mathrm{v} . \% \mathrm{H}_{2}$ which is the minimal amount required to reach $\lambda=2$, and without $H_{2}$. In the following paragraphs, the amount of $\mathrm{H}_{2}$ added at the intake is given as a fraction of the intake volume flow rate (air and hydrogen). Since a negative valve overlap was used for the tests, hydrogen was not directly scavenged towards the exhaust but remained in the combustion chamber.

- At mid-load (3000 rpm - 13 bar IMEP at $\lambda=2$ ): the main objective was to highlight the positive impacts of $\mathrm{H}_{2}$ on combustion speed and auto-ignition at similar non-optimal combustion timings. For this operating point, two calculations have been performed, with 3 v/v. \% $H_{2}$ which is the minimal amount required to reach $\lambda=2$, and without $H_{2}$. It can be noted that the peak efficiency for the considered engine was obtained for this operating point during the experimental test campaign. 3D calculations performed for this operating point can thus also be used to numerically assess the heat balance in optimal conditions.

When they are available, experimental measurements are used as boundary conditions for numerical calculations (see Table 6). Without hydrogen, no experimental data was logically available at $\lambda=2$ since this high dilution rate cannot be reached with a classical ignition system (usual limits for the considered operating points are of around 1.6 to 1.7).

\begin{tabular}{c|c|c|c|c} 
Speed [rpm] & IMEP [bar] & $H_{2}[\mathrm{v} / \mathrm{v} . \%]$ & $\lambda[-]$ & Exp. data \\
\hline \multirow{2}{*}{2000} & \multirow{2}{*}{4} & 3 & 2 & Yes \\
\cline { 3 - 5 } & \multirow{2}{*}{3000} & 0 & 2 & No \\
\hline \multirow{2}{*}{13} & 3 & 2 & Yes \\
\cline { 3 - 5 } & & 0 & 2 & No \\
\hline
\end{tabular}

Table 6. Available experimental data for numerical calculations.

\section{CONVERGE simulations}

The 3D-RANS simulations presented in the framework of this paper were performed using the solver CONVERGE (42; 43).

Combustion is modeled by the Extended Coherent Flame Model (ECFM) model (44; 45). It relies on a flame surface density equation which takes into account the wrinkling of the flame front surface by turbulent eddies. To represent physical phenomena describing ignition, the ISSIM model (46), adapted for RANS formalism, is used. The model is divided into two parts: after an initial burned gases deposit, the flame kernel growth is modeled thanks to a modified flame surface density equation. The ignition data is obtained through the look up table or TKI-table discussed earlier.

Concerning turbulence, the $\mathrm{k}-\epsilon$ RNG model is used, along with a law-of-the-wall approach (47) to model the turbulence kinetic energy and dissipation within boundary layer. Thermal heat fluxes at the wall boundaries are calculated using the wall heat transfer model of O'Rourke and Amsden (48). 
The liquid injection is modeled using the blob injection approach (49): the characteristic size of the injected parcels are equal to the effective diameter of the nozzle. The Kelvin-Helmhotz (KH) and Rayleigh-Taylor (RT) instability mechanisms are used to model the spray breakup (43). The interactions between spray and walls rely on a particle-based approach. In particular, the liquid film transport follows the model of O'Rourke and Amsden (50).

The gaseous computational domain is automatically discretized using the cut-cell Cartesian method implemented in CONVERGE. In the whole domain, mesh size is equal to $2 \mathrm{~mm}$ and some regions are locally refined to capture physics phenomena. To ensure sufficient grid refinement during the combustion phase, fixed embedding are used in the liquid spray region and along the walls (see Figures $8 \mathrm{~b}$ and $9 \mathrm{~b}$ ). The mesh size near the wall is around $0.25 \mathrm{~mm}$. During the combustion phase, a refined region is defined around the spark plug where the mesh size is equal to $0.5 \mathrm{~mm}$. In addition, the Adaptive Mesh Refinement tool is also used to apply a local refinement of the grid in the regions of strong gradients of velocity and temperature. This method enables to divide by two the mesh sizes in some regions, in particular during flame propagation or spray injection in order to capture respectively the flame front propagation and the spray dynamics.

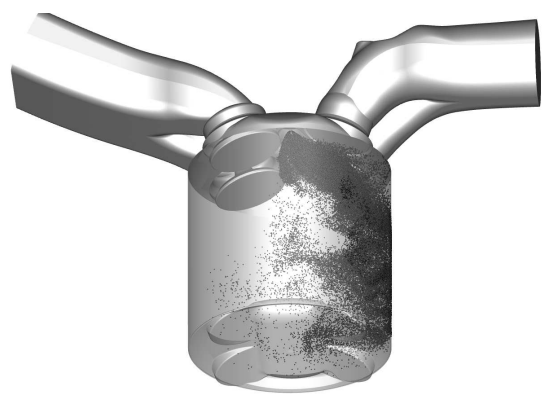

(a) Spray Visualization

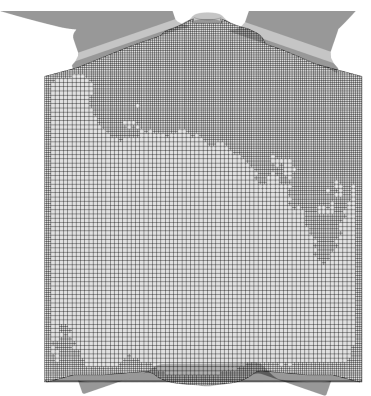

(b) Injection Phase Mesh

Figure 8. 3D visualization of the injection phase, $43 \mathrm{CAD}$ after SOI.

\section{D Methodology to take into account $\mathrm{H}_{2}$}

Complex chemistry calculations in homogeneous reactors were first performed in order to quantify the impacts of $\mathrm{H}_{2}$ on the laminar flame speed and on the auto-ignition delay times which are the two main characteristics that must be taken into account for an accurate modeling of the combustion process. From a numerical point of view, $\mathrm{H}_{2}$ is taken into account in the laminar flame speed correlation

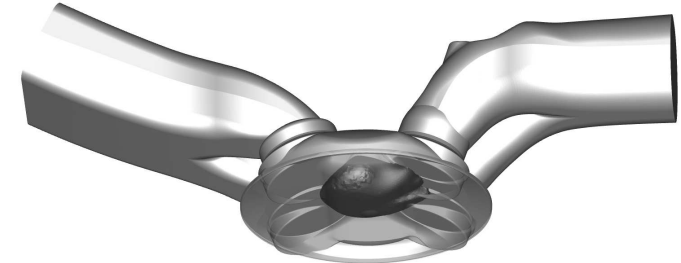

(a) Flame Front Visualization

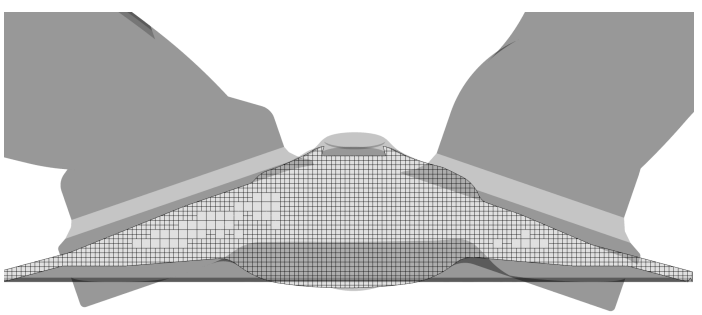

(b) Combustion Phase Mesh

Figure 9. 3D visualization of the combustion phase, $19 \mathrm{CAD}$ after ST.

used by ECFM model for the flame front propagation and in the generation of the auto ignition delay times tables used by the TKI model. The implemntation of the new laminar flame speed in the ECFM model has been validated thanks to specific test cases (not shown in this article) and several calculations in homogeneous reactors were performed with CONVERGE and with the TKI model in order to validate the implementation of the new auto-ignition delay times tables. These calculations aimed at showing that the TKI model is able to reproduce the same auto-ignition delay as those obtained with zero dimensional calculations performed in a previous section and the complex chemistry (that cannot be directly used for 3D CFD engine calculations because of computational time). Figures $10 \mathrm{a}$ and $10 \mathrm{~b}$ compare the temperature evolution between the complex chemistry and the 3D calculations for different $\lambda$. The 3D CONVERGETKI methodology is able to reproduce the auto-ignition of ultra-lean and stoichiometric mixture with and without $\mathrm{H}_{2}$ supplementation. Figure 10a shows a weak increase of the auto-ignition delay for the $3 \mathrm{D}$ calculations because of the lower refinement of the TKI table for this range of equivalence ratio. These academic cases show however that $H_{2}$ effect on auto-ignition can be well reproduced for 3D engines calculations.

\section{Numerical investigations on $H_{2}$ enhanced combustion}

As shown in Table 6, some experimental data were not available since operating points at $\lambda=2$ cannot be reached without $\mathrm{H}_{2}$ supplementation because of the flammability limits of air/gasoline mixtures. The methodology used to simulate these operating conditions consisted in performing first the calculations with $\mathrm{H}_{2}$, and then in modifying the in-cylinder species field before the combustion, namely by 


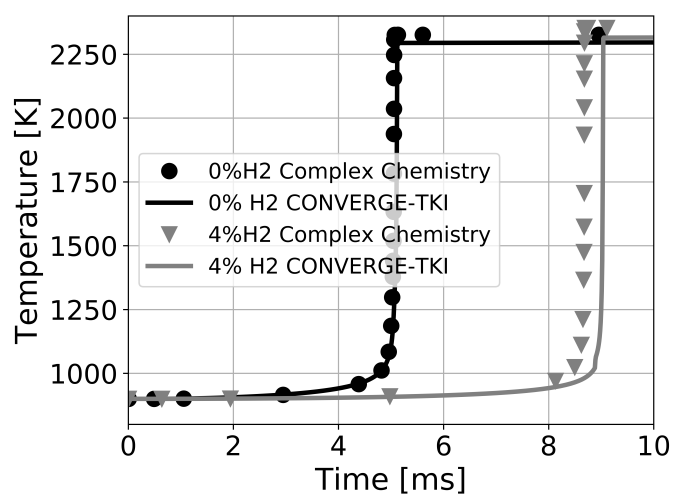

(a) $\lambda=2.0$

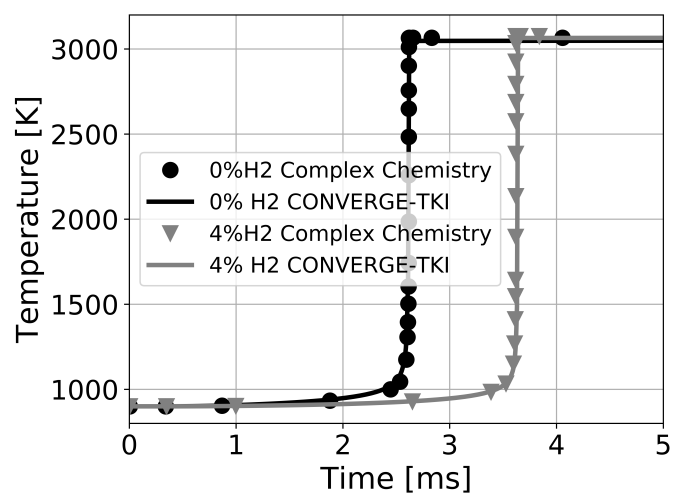

(b) $\lambda=1.0$

Figure 10. Impact of $\mathrm{H}_{2}$ on auto-ignition in homogeneous reactor (40 bar, $900 \mathrm{~K}$ without dilution).

replacing the hydrogen mass fraction by the same mass fraction of E10 surrogate and the global equivalence ratio remains constant. It must be noted that the combustion model have been fitted beforehand by comparison with experimental data at $2000 \mathrm{rpm}, 18$ bar IMEP, $\lambda=1$ (not show in this article). Then, the same parameters have been used for calculations at $\lambda=2$ (with and without hydrogen). The following analysis is performed on the second combustion cycle, to ensure that initial conditions are non-intrusive. TDC is located at $720 \mathrm{CAD}$ for more clarity.

\section{Low Load: 2000 rpm - 4 bar}

For this operating point, two kinds of comparisons can be performed. First, a comparison between numerical and experimental results obtained with $3 \mathrm{v} / \mathrm{v} . \%$ of hydrogen can be performed at $\lambda=2$. On the other hand, thanks to calculations results, it is also possible to compare the combustion process at $\lambda=2$ with and without hydrogen.

Figure 11a compares the temporal in-cylinder experimental pressure with the numerical results obtained with and without hydrogen. Dashed lines in Figure 11a show the maximal cycle-to-cycle fluctuations for experimental results (over 300 cycles). A good agreement was found between experimental and numerical results obtained with $\mathrm{H}_{2}$, with similar combustion timings and similar peak firing pressures. This first observation shows that 3D software CONVERGE and its combustion models can be actually used to simulate the combustion process with hydrogen at $\lambda=2$, even when these models are fitted at $\lambda=1$.

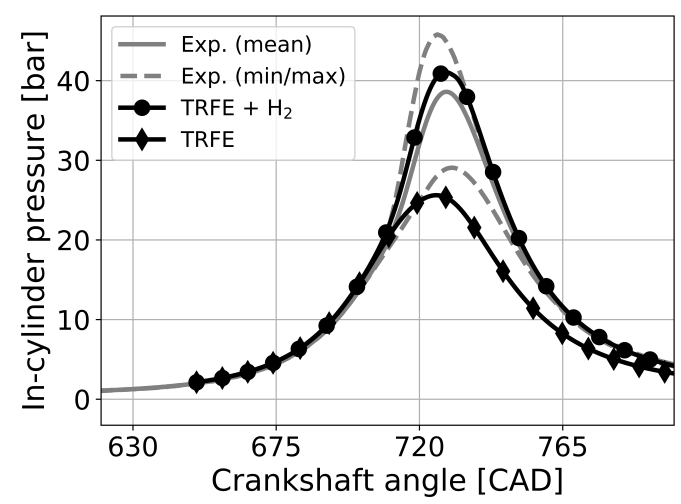

(a)

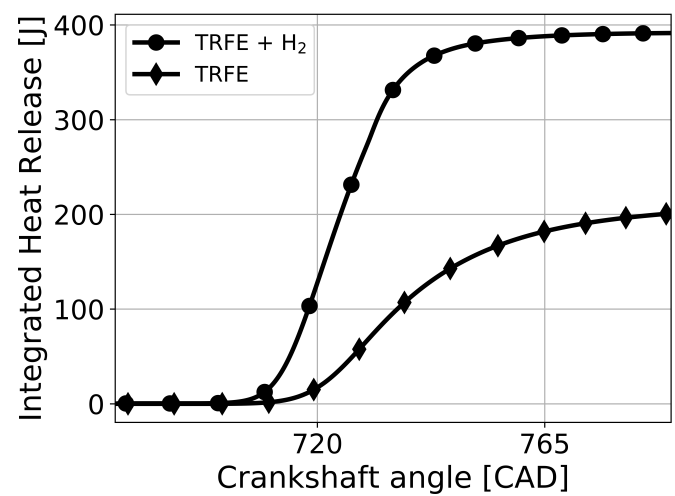

(b)

Figure 11. Comparison of experimental and numerical in-cylinder pressure evolution (a) and integrated heat release with and without hydrogen (b).

The average $\lambda$ value is the same for calculations with and without hydrogen but the use of hydrogen clearly improves the combustion speed, through the laminar flame speed correlation. As shown in Figure 11a and Figure 11b, the use of hydrogen allows to burn all the air/fuel mixture in the cylinder whereas in the case without hydrogen, around half of the mixture is burnt. Such a combustion process could not be reproduced experimentally because the combustion speed is way too slow and the resulting cycle-to-cycle fluctuations would be too high. As it was found experimentally, 3D calculations show that the use of hydrogen is required to reach $\lambda=2$ while maintaining an efficient combustion process.

To better understand why the combustion process is slowed down without hydrogen, Figure 12a shows the laminar flame speed integrated over the flame front for both cases with and without hydrogen. These results show for example that the maximal laminar flame speed is doubled when hydrogen is used (from around $0.45 \mathrm{~m} / \mathrm{s}$ up to $0.9 \mathrm{~m} / \mathrm{s}$ ). It can also be noted that this maximal value of around $0.9 \mathrm{~m} / \mathrm{s}$ is in the same order of magnitude of what could be expected at $\lambda=1$ without any dilution for the considered pressure and temperature conditions.

Coherently with the laminar flame speeds shown in Figure 12a, rates of heat release (including premixed 
combustion and auto-ignition) plotted in Figure $12 \mathrm{~b}$ show that the combustion speed is increased with hydrogen. It is interesting to note that critical combustion instabilities can be usually experimentally observed when the maximal rate of heat release is lower than $0.04 \mathrm{CAD}^{-1}$ which is the maximal value that is predicted here by $3 \mathrm{D}$ calculations without hydrogen. It is shown for example by de Francqueville and Michel with EGR at high load (51), and it can also be derived from the results reported in lean conditions by Hanabusa et al. (52). The minor peak of heat release rate occurring with hydrogen around $730 \mathrm{CAD}$ is due to a weak auto-ignition process (heat released by auto-ignition being here far below the usual threshold for detecting knock, confirming thus of course that no knock occurs for this low load operating point).

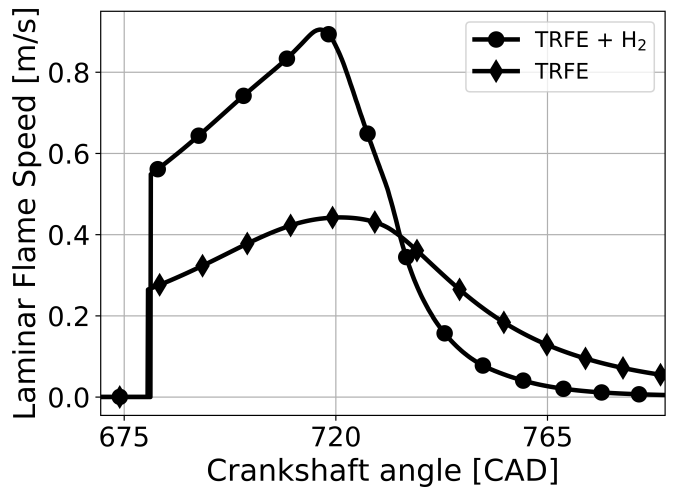

(a)

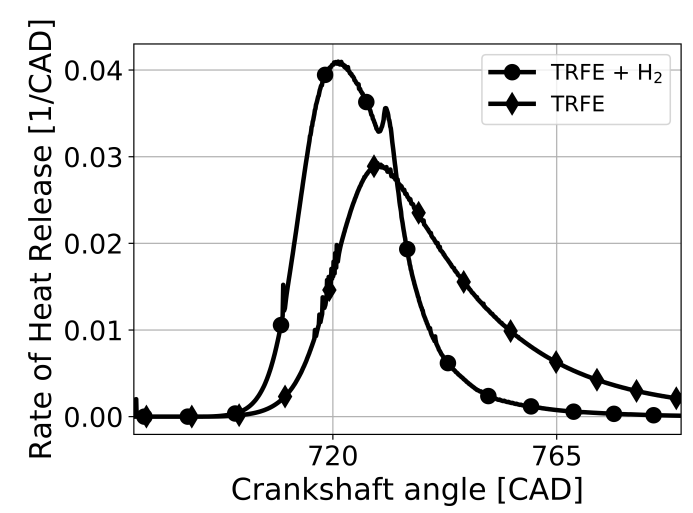

(b)

Figure 12. Evolution of the laminar flame speed integrated over the flame front (a) and the rate of heat release (b) with and without hydrogen.

This flame speed variation illustrates the positive effect on hydrogen on the combustion process but it is also interesting to focus on the beginning of combustion by analyzing the angular duration between spark timing and the CA05 angle (crankshaft angle for which 5\% of the fuel is burnt). With hydrogen, this angular duration is of around $17 \mathrm{CAD}$, and it increases up to 26.7 CAD without hydrogen ( $56 \%$ increase). This improvement shows that hydrogen can enhance not only the maximal combustion speed, but also the flame growth just after the spark at the very beginning of combustion which is a critical aspect of combustion with diluted mixtures. Figure 13

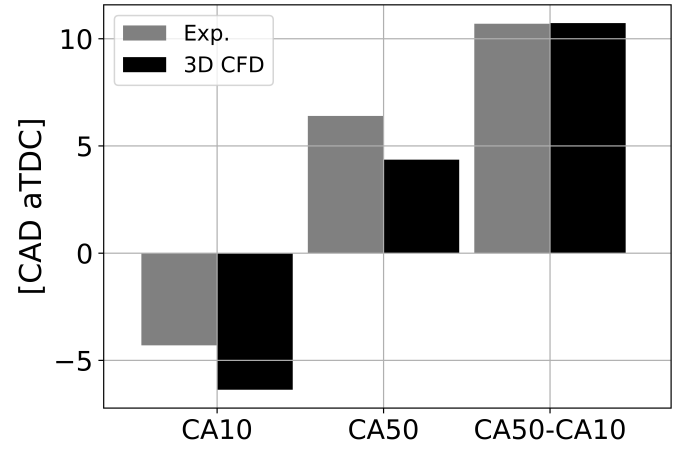

Figure 13. Comparison of CA10 and CA50 for experimental and numerical results with $\mathrm{H}_{2}$.

also compares the crankshaft angles for which 10 and $50 \%$ of the fuel is burnt for experimental results and for the calculations results with hydrogen. Overall, a good agreement between experimental and numerical results can be observed. The optimal combustion timing CA50 was set at the test bench at around 7 CAD aTDC and a similar but slightly advanced combustion timing is obtained with 3D calculations performed with the same spark-timing as for the experimental tests. The same observation can be made for the CA10 angles: 3D calculations show a slightly earlier CA10 than the experiments. In fact, the duration of the first half of combustion is exactly the same for experiments and calculations, but the combustion process predicted by calculations occurs slightly earlier than for the experiments (around 2 CAD earlier).

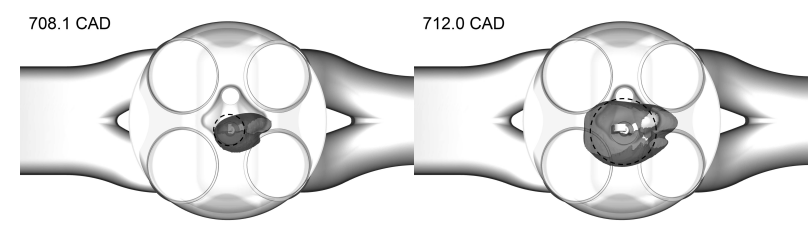

(a) $15.5 \mathrm{CAD}$ after $\mathrm{ST}$

(b) $19.5 \mathrm{CAD}$ after ST

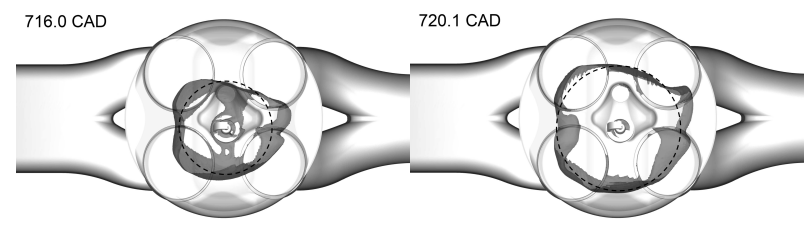

(c) 23.5 CAD after ST

(d) 27.4 CAD after ST

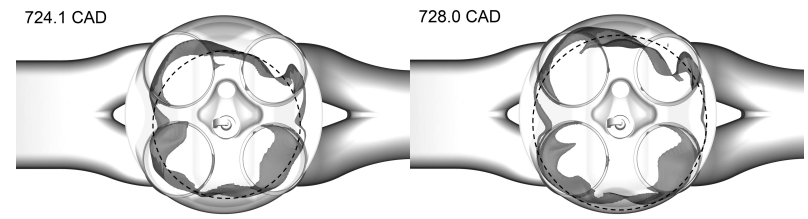

(e) 31.5 CAD after ST

(f) 35.5 CAD after ST

Figure 14. 3D visualization of the flame front propagation (CFM progress variable $=0.99$ ). The dashed line represents a fictive spherical propagation. 


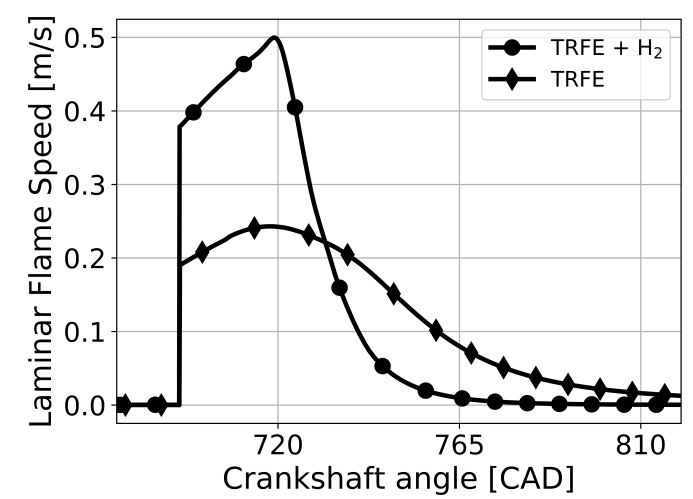

(a)

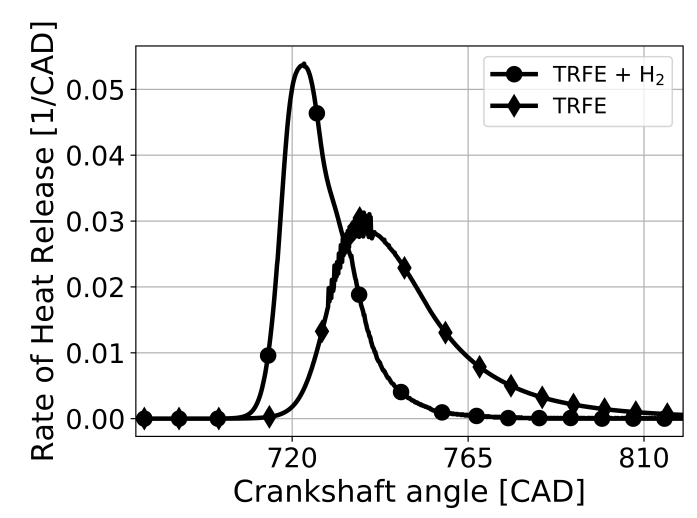

(b)

Figure 17. Evolution of the laminar flame speed integrated on the flame front (a) and the rate of heat release (b) with and without hydrogen.

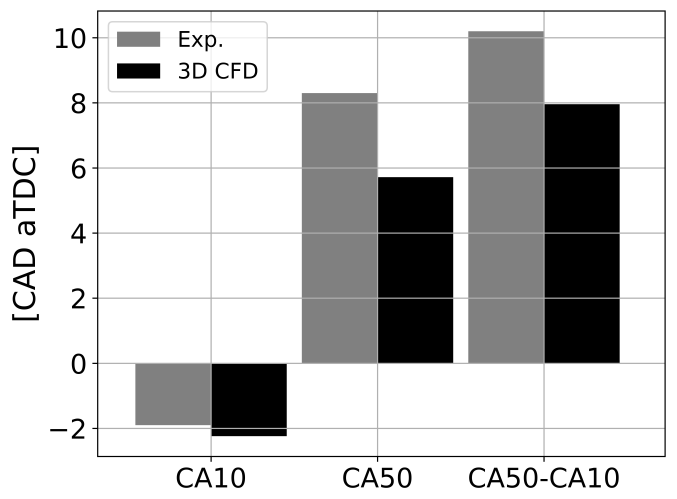

Figure 18. Experimental and numerical comparison of characteristic combustion timings.

combustion process, as shown in Figures 20a and 20b, which is in agreement with results shown in Figure 19. Figures 20c and 20d show then the potential auto-ignition zones in the combustion chamber. Because of the fuel consumption by the flame propagation, no auto-ignition is occurring in theses zones, where temperature is high. It explains why AI is located behind the flame front propagation in Figures 20c and $20 \mathrm{~d}$. The AI progress variable only highlights potential AI areas but as the fuel has already been consumed, no AI occurs behind the flame front. However, the weak increase of the auto-ignition reaction rate observed in Figure 19 around

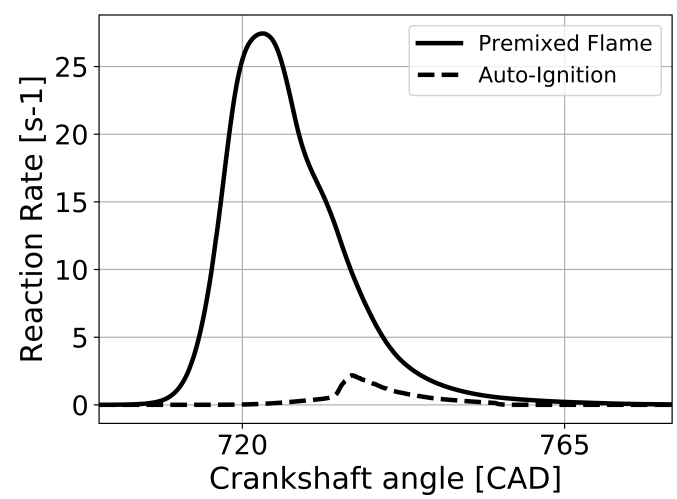

Figure 19. Comparison between the reaction rate of the premixed flame and the auto-ignition for the case at $\lambda=2$ with $3 \mathrm{v} / \mathrm{v} . \%$ of hydrogen.

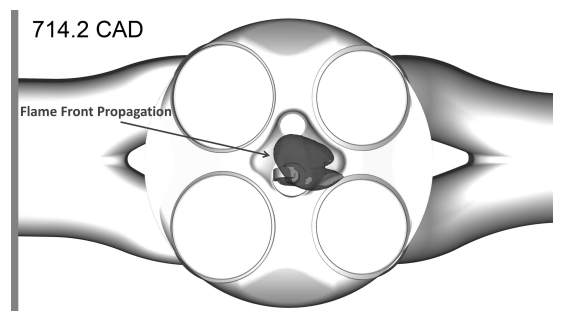

(a) 16 CAD after ST

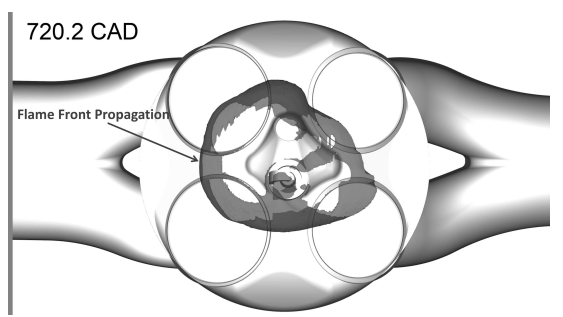

(b) 22 CAD after ST

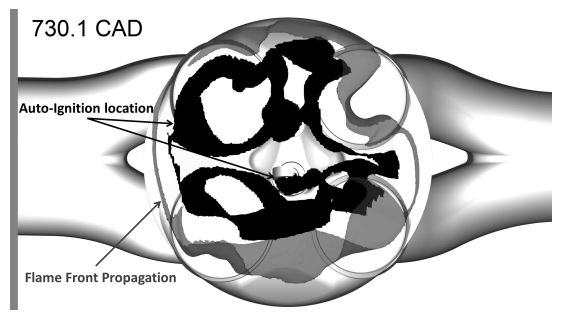

(c) 32 CAD after ST

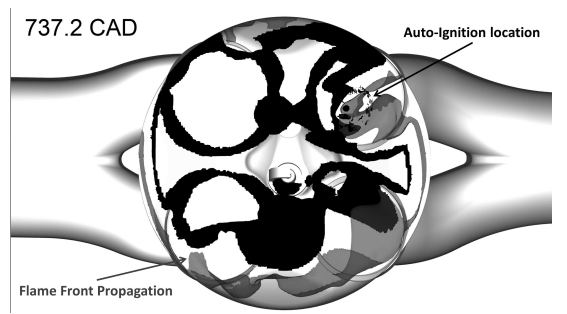

(d) 39 CAD after ST

Figure 20. 3D visualization of the flame front propagation (CFM progress variable $=0.99$, represented in grey) and the auto-ignition location (TKI progress variable $=0.99$, represented in black). 


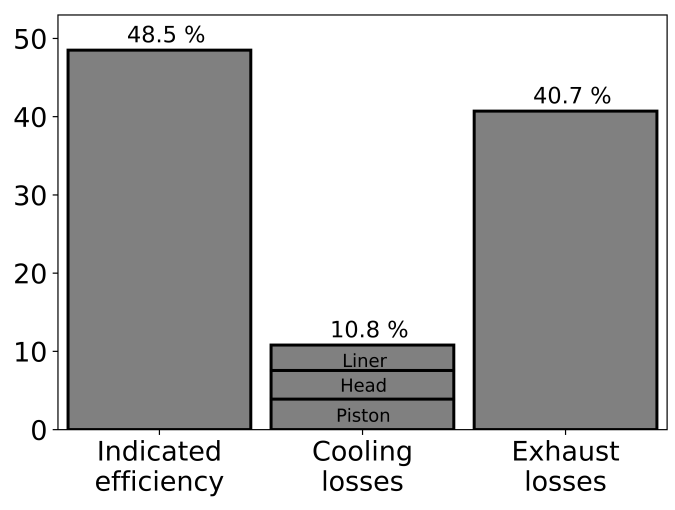

Figure 21. Global energy distribution of the combustion system.

737 CAD can also be observed in Figure 20d where autoignition and flame propagation are interwoven (under one of the exhaust valves).

Eight operating points were experimentally investigated and the maximal efficiency was obtained for these operating conditions at $3000 \mathrm{rpm}, 13$ bar IMEP, and at $\lambda=2$. Heat balances for experimental and numerical results cannot be directly compared because different models and methodologies are used to quantify these heat balances in both cases. However, it is interesting to note that similar orders of magnitude are obtained. For this operating point, the total heat loss inside the combustion chamber (excluding thus intake and exhaust ports) was close to $12 \%$ according to the experimental results, and is here close to $10.8 \%$ based upon 3D calculation results (around $128 \mathrm{~J}, 36 \%$ for the piston, 34\% for the cylinder head, and 30\% for the liner, see Figure 21). In parallel, a maximal indicated efficiency of $47.3 \%$ was obtained during experiments while the indicated efficiency calculated based upon 3D calculations results is of $48.5 \%$. This higher efficiency is, however, consistent with the earlier combustion timing (see Figure 18) and with the higher combustion speed obtained through calculations (see Figure $17 \mathrm{~b}, 0.055 \mathrm{CAD}^{-1}$ and $0.046 \mathrm{CAD}^{-1}$ for numerical and experimental results respectively).

\section{Conclusion}

The main objective of this study was to perform 3D CFD engine calculations in order to numerically analyze the hydrogen effects by comparing numerical results with experimental data. To do so, the effects of hydrogen on the laminar flame speed and on auto-ignition delay times have first been evaluated through chemical kinetics calculations. The new laminar flame speed correlation and tabulated auto-ignition delay times have been implemented in the CONVERGE CFD code and validated thanks to reference test cases. Then, the positive impacts of hydrogen have been numerically demonstrated for two different operating points at $\lambda=2$ through 3D CFD engine calculations. Thanks to the updated ECFM and TKI models, 3D engine calculations firstly show that the experimental combustion process observed at $\lambda=2$ can be numerically reproduced which is already a significant achievement since these conditions are very far from the usual operating conditions of SI engines.
Moreoever, thanks to these numerical investigations, it is also possible to analyze more precisely the positive effects of hydrogen at $\lambda=2$. At low load, the homogeneous hydrogen concentration supports a nearly spherical flame propagation despite the air/gasoline ratio heterogeneities. At mid load, hydrogen demonstrated not only a positive effect on the combustion velocity but also as expected on the auto-ignition resistance. No variation has been performed regarding the amount of hydrogen used to enhance the combustion process since one of the main effect expected for this kind of variation is the improvement in combustion stability, which cannot be analyzed through RANS calculations. In this context, Large-Eddy Simulations could be interesting to determine the minimal amount of hydrogen to reach a targeted $\lambda$ level.

\section{Acknowledgement}

The project leading to this application has received funding from the European Union's Horizon 2020 research and innovation programme under grant agreement No 724084

\section{Nomenclature}

CAD: Crankshaft Angle Degree

ECFM: Extended Coherent Flame model

EGR: Exhaust Gas Recirculation

EIVC: Early Intake Valve Closing

EVC: Exhaust Valve Closing

IMEP: Indicated Mean Effective Pressure

IVO: Intake Valve Opening

SI: Spark Ignition

SOI: Start Of Injection (for E10 fuel)

ST: Spark-Timing

TDC: Top Dead Center

aTDC: After Top Dead Center

TKI: Tabulated Kinetics of Ignition

$\lambda:$ Air-fuel ratio

CA10: crankshaft angle for which $10 \%$ of fuel mass is burnt CA50: crankshaft angle for which 50\% of fuel mass is burnt

\section{References}

[1] Sayama S, Kinoshita M, Mandokoro Y et al. Spark ignition and early flame development of lean mixtures under high-velocity flow conditions: An experimental study. International Journal of Engine Research 2019; 20(2): 236-246.

[2] Das L. Exhaust emission characterization of hydrogenoperated engine system: Nature of pollutants and their control techniques. International Journal of Hydrogen Energy 1991; 16(11): 765-775.

[3] Sastri M. Hydrogen energy research and development in India-an overview. International Journal of Hydrogen Energy 1987; 12(3): 137-145.

[4] Al-Janabi HAKS and Al-Baghdadi MARS. A prediction study of the effect of hydrogen blending on the performance and pollutants emission of a four stroke spark ignition engine. International Journal of Hydrogen Energy 1999; 24(4): 363-375. 
[5] Hari Ganesh R, Subramanian V, Balasubramanian $\mathrm{V}$ et al. Hydrogen fueled spark ignition engine with electronically controlled manifold injection: An experimental study. Renewable Energy 2008; 33(6): 1324-1333.

[6] Akansu S, Kahraman N and Ceper B. Experimental study on a spark ignition engine fuelled by methanehydrogen mixtures. International Journal of Hydrogen Energy 2007; 32(17): 4279-4284.

[7] Huang Z, Liu B, Zeng K et al. Experimental Study on Engine Performance and Emissions for an Engine Fueled with Natural Gas-Hydrogen Mixtures. Energy \& Fuels 2006; 20(5): 2131-2136.

[8] Porpatham E, Ramesh A and Nagalingam B. Effect of hydrogen addition on the performance of a biogas fuelled spark ignition engine. International Journal of Hydrogen Energy 2007; 32(12): 2057-2065.

[9] Sadiq Al-Baghdadi MAR and Shahad Al-Janabi HAK. Improvement of performance and reduction of pollutant emission of a four stroke spark ignition engine fueled with hydrogen-gasoline fuel mixture. Energy Conversion and Management 2000; 41(1): 77-91.

[10] Houseman J and Hoehn FW. A Two-Charge Engine Concept: Hydrogen Enrichment. In International Stratified Charge Engine Conference. SAE Technical Paper Series, SAE International400 Commonwealth Drive, Warrendale, PA, United States.

[11] Dunn-Rankin D. Lean combustion: technology and control. Elsevier, 2011.

[12] Sankaran R and Im H. Effects of hydrogen addition on the Markstein length and flammability limit of stretched Methane/Air premixed flames. Combustion Science and Technology 2006; 178(9): 1585-1611.

[13] Ji C and Wang S. Effect of hydrogen addition on combustion and emissions performance of a spark ignition gasoline engine at lean conditions. International Journal of Hydrogen Energy 2009; 34(18): 7823-7834.

[14] Ji C and Wang S. Combustion and emissions performance of a hybrid hydrogen-gasoline engine at idle and lean conditions. International Journal of Hydrogen Energy 2010; 35(1): 346-355.

[15] Ji C, Wang S, Zhang B et al. Emissions performance of a hybrid hydrogen-gasoline engine-powered passenger car under the New European Driving Cycle. Fuel 2013; 106: 873-875.

[16] Varde KS. Combustion Characteristics of Small Spark Ignition Engines Using Hydrogen Supplemented Fuel Mixtures. In 1981 SAE International Off-Highway and Powerplant Congress and Exposition. SAE Technical Paper Series, SAE International400 Commonwealth Drive, Warrendale, PA, United States.

[17] Tahtouh T, Halter F, Samson E et al. Effects of hydrogen addition under lean and diluted conditions on combustion characteristics and emissions in a sparkignition engine. International Journal of Engine Research 2011; 12(5): 466-483.

[18] Dandrea T. The addition of hydrogen to a gasolinefuelled SI engine. International Journal of Hydrogen Energy 2004; 29(14): 1541-1552.
[19] Gerke U and Boulouchos K. Three-dimensional computational fluid dynamics simulation of hydrogen engines using a turbulent flame speed closure combustion model. International Journal of Engine Research 2012; 13(5): 464-481.

[20] Sarathy S, Farooq A and Kalghatgi G. Recent progress in gasoline surrogate fuels. Progress in Energy and Combustion Science 2018; 65: 67-108.

[21] CHEMKIN-PRO. 15131, Reaction Design: San Diego, 2013.

[22] Bounaceur R, Herbinet O, Fournet R et al. Modeling the Laminar Flame Speed of Natural Gas and Gasoline Surrogates. In SAE 2010 World Congress \& Exhibition. SAE Technical Paper Series, SAE International400 Commonwealth Drive, Warrendale, PA, United States.

[23] Ranzi E, Frassoldati A, Grana R et al. Hierarchical and comparative kinetic modeling of laminar flame speeds of hydrocarbon and oxygenated fuels. Progress in Energy and Combustion Science 2012; 38(4): 468-501.

[24] Shebeko Y, Tsarichenko S, Korolchenko A et al. Burning velocities and flammability limits of gaseous mixtures at elevated temperatures and pressures. Journal of Engineering for Gas Turbines and Power 1995; 102(4): 427-437.

[25] Iijima $\mathrm{T}$ and Takeno $\mathrm{T}$. Effects of temperature and pressure on burning velocity. Combustion and Flame 1986; 65(1): 35-43.

[26] Qin X, Kobayashi H and Niioka T. Laminar burning velocity of hydrogen-air premixed flames at elevated pressure. Experimental Thermal and Fluid Science 2000; 21(1): 58-63.

[27] Aung K, Hassan M and Faeth G. Effects of pressure and nitrogen dilution on flame/stretch interactions of laminar premixed $\mathrm{H} 2 / \mathrm{O} 2 / \mathrm{N} 2$ flames. Combustion and Flame 1998; 112(1): 1-15.

[28] Krejci M, Mathieu O, Vissotski A et al. Laminar Flame Speed and Ignition Delay Time Data for the Kinetic Modeling of Hydrogen and Syngas Fuel Blends. Journal of Engineering for Gas Turbines and Power 2013; 135(2).

[29] Bouvet N, Halter F, Chauveau C et al. On the effective Lewis number formulations for lean hydrogen/hydrocarbon/air mixtures. International Journal of Hydrogen Energy 2013; 38(14): 5949-5960.

[30] Mandilas C, Ormsby M, Sheppard C et al. Effects of hydrogen addition on laminar and turbulent premixed methane and iso-octane air flames. Proceedings of the Combustion Institute 2007; 31(1): 1443-1450.

[31] Li Z, Han W, Liu D et al. Laminar flame propagation and ignition properties of premixed iso-octane/air with hydrogen addition. Fuel 2015; 158: 443-450.

[32] D'Adamo A, Del Pecchia M, Breda S et al. ChemistryBased Laminar Flame Speed Correlations for a Wide Range of Engine Conditions for Iso-Octane, n-Heptane, Toluene and Gasoline Surrogate Fuels. In International Powertrains, Fuels and Lubricants Meeting. SAE International.

[33] Eisazadeh-Far K, Moghaddas A, Al-Mulki J et al. Laminar burning speeds of ethanol/air/diluent mixtures. Proceedings of the Combustion Institute 2011; 33(1): 
1021-1027.

[34] Gulder O. Burning velocities of ethanol-isooctane blends. Combustion and Flame 1984; 56(3): 261-268.

[35] Tahtouh T, Halter F and Mounaim-Rousselle C. Laminar premixed flame characteristics of hydrogen blended iso-octane air nitrogen mixtures. International Journal of Hydrogen Energy 2011; 36(1): 985-991.

[36] Duan J and Liu F. Laminar combustion characteristics and mechanism of hydrogen/air mixture diluted with $\mathrm{N} 2$ and H2O. International Journal of Hydrogen Energy 2017; 42(7): 4501-4507.

[37] Colin O, Pires da Cruz A and Jay S. Detailed chemistry-based auto-ignition model including low temperature phenomena applied to 3-D engine calculations. Proceedings of the Combustion Institute 2005; 30(2): 2649-2656.

[38] Knop V, Michel JB and Colin O. On the use of a tabulation approach to model auto-ignition during flame propagation in SI engines. Applied Energy 2011; 88(12): 4968-4979.

[39] Mehl M, Pitz W, Westbrook C et al. Kinetic modeling of gasoline surrogate components and mixtures under engine conditions. Proceedings of the Combustion Institute 2011; 33(1): 193-200.

[40] Jain S, Li D and Aggarwal S. Effect of hydrogen and syngas addition on the ignition of iso-octane and air mixtures. International Journal of Hydrogen Energy 2013; 38(10): 4163-4176.

[41] An H, Chung J and Soonho S. The effects of hydrogen addition on the auto-ignition delay of homogeneous primary reference fuelair mixtures in a rapid compression machine. International Journal of Hydrogen Energy 2015; 40(40): 13994-14005.

[42] Galpin J, Colliou T, Laget $\mathrm{O}$ et al. Design of a Fuel-Efficient Two-Stroke Diesel Engine for Medium Passenger Cars: Comparison between Standard and Reverse Uniflow Scavenging Architectures. In $W C X^{T M}$ 17: SAE World Congress Experience. SAE Technical Paper Series, SAE International400 Commonwealth Drive, Warrendale, PA, United States.

[43] Senecal PK, Richards KJ, Pomraning E et al. A New Parallel Cut-Cell Cartesian CFD Code for Rapid Grid Generation Applied to In-Cylinder Diesel Engine Simulations. In SAE World Congress \& Exhibition. SAE Technical Paper Series, SAE International400 Commonwealth Drive, Warrendale, PA, United States.

[44] Chevillard S, Colin O, Bohbot J et al. Advanced Methodology to Investigate Knock for Downsized Gasoline Direct Injection Engine Using 3D RANS Simulations. In $W C X^{T M}$ 17: SAE World Congress Experience. SAE Technical Paper Series, SAE International400 Commonwealth Drive, Warrendale, PA, United States.

[45] Colin O, Benkenida A and Angelberger C. 3d Modeling of Mixing, Ignition and Combustion Phenomena in Highly Stratified Gasoline Engines. Oil \& Gas Science and Technology 2003; 58(1): 47-62.

[46] Colin O and Truffin K. A spark ignition model for large eddy simulation based on an FSD transport equation (ISSIM-LES). Proceedings of the Combustion Institute
2011; 33(2): 3097-3104.

[47] Launder BE and Spalding DB. The numerical computation of turbulent flows. Computer Methods in Applied Mechanics and Engineering 1974; 3(2): 269289.

[48] Amsden AA and Findley M. KIVA-3V: A BlockStructured KIVA Program for Engines with Vertical or Canted Valves 1997; .

[49] Reitz R and Diwakar R. Structure of HighPressure Fuel Sprays. In SAE International Congress and Exposition. SAE Technical Paper Series, SAE International400 Commonwealth Drive, Warrendale, PA, United States.

[50] P J O'Rourke and A A Amsden. A Spray Wall Interaction Submodel for the KIVA-3 Wall Film Model. SAE Transactions 2000; 109: 281-298.

[51] de Francqueville L and Michel J. On the Effects of EGR on Spark-Ignited Gasoline Combustion at High Load. pp. 1808-1823.

[52] Hanabusa H, Kondo T, Hashimoto K et al. Study on Homogeneous Lean Charge Spark Ignition Combustion. In SAE/KSAE 2013 International Powertrains, Fuels Lubricants Meeting. SAE Technical Paper Series, SAE International400 Commonwealth Drive, Warrendale, PA, United States. 